Madhuwanthi, B.G.K. and Somachandra, V., 2019. Corporate social responsibility practices for sustainability: Case of Sri Lankan cement manufacturing and supplying organisations. In: Sandanayake, Y.G., Gunatilake, S. and Waidyasekara, A. (eds). Proceedings of the $8^{\text {th }}$ World Construction Symposium, Colombo, Sri Lanka, 8-10 November 2019, pp. 220-230. DOI: doi.org/10.31705/WCS.2019.22. Available at: https://2019.ciobwcs.com/papers

\title{
CORPORATE SOCIAL RESPONSIBILITY PRACTICES FOR SUSTAINABILITY: CASE OF SRI LANKAN CEMENT MANUFACTURING AND SUPPLYING ORGANISATIONS
}

\author{
Borug Gamage Kaushalya Madhuwanthi ${ }^{1}$ and Vathsala Somachandra ${ }^{2}$
}

\begin{abstract}
Construction industry is a booming industry worldwide and achieving sustainability in the construction industry has become a vital ambition. Nowadays, the concept of sustainability with its triple bottom line meaning is being adopted more and more by corporations and concerning construction trade, sustainability is about achieving a winwin output. Cement organisations' business is a crucial sub-segment of the construction industry. Apart from the frequent monetary benefits from the cement organisations, it is increasingly linked to various unethical business practices form numerous challenges that threaten sustainability in cement industry. Thus, in the direction to achieve corporate sustainability; Corporate Social Responsibility (CSR) was recognized as an effective tool. Sri Lankan cement manufacturing and supplying organizations usually publish details about CSR practices of the philanthropic, business environment and business process in their annual business reports. Therefore, this qualitative study based on five in-depth interviews focused on identifying the Sri Lankan cement companies' gap between their current practice and required practice of CSR within their business process. The results found could be categorised under three main sectors as CSR through philanthropic activities, CSR related to business environment and CSR related to business process. It was found that; Sri Lankan cement organizations' CSR practices related to philanthropic and business environment were at highest level. Even though there is a significant lacking point in the current practices of CSR linked to the business process and application of sustainable innovations for cement organisations' business process to achieve corporate sustainability.
\end{abstract}

Keywords: Cement Organisation; Construction Industry; Corporate Social Responsibility (CSR); Sri Lanka; Sustainability.

\section{INTRODUCTION}

Construction industry is one of the major booming industries in the world (Tradesmen, 2018). The ongoing growth and expansion of construction industry is progressively related to several sustainable improvement challenges, comprising various economic, environmental and social impacts (Shen et al., 2010). Murray and Dainty (2009) stated

\footnotetext{
${ }^{1}$ Computing, Engineering and the Built Environment, Birmingham City University, Sri Lanka, kaushalyamadu94@gmail.com

${ }^{2}$ Faculty of Construction and Engineering, International College of Business \& Technology, Sri Lanka, vathsala@icbtcampus.edu.lk
} 
that the construction industry activities from the commencement to occupying and demolishing phase and their impacts on the environment, economy and society is significant. According to the Central Bank's Statistics Report (2017), the Sri Lankan construction industry, categorised under the industrial sector, contributed $26.8 \%$ of sectorial composition from economic activities to the GDP in 2016. Moreover, highest labour opportunities were noted from the construction industry under industrial sector (Department of Census and Statistics, 2017). However, more than 30 persons on average are admitted daily to the Colombo National Hospital due to the increasing number of construction workplace accidents (Warakapitiya, 2016).

Considering above economical, societal and environmental impacts from the Sri Lankan construction industry, achieving sustainability in construction industry has become a vital ambition of the country (Bal et al., 2013). The basic concept of sustainability is to provide long-standing affordability, quality and efficiency, importance to occupants and clients of buildings whereas reducing harmful ecological impressions and accelerating the profitable sustainability (Bal et al., 2013). To achieve construction industry sustainability, it is necessary to achieve sustainability in the construction business as it is an interwoven trade in the triple bottom line of economy, environment and society (Somachandra and Sylva, 2017). Nevertheless, concerning construction trade, sustainability is about achieving a win-win output (Shen et al., 2010).

Creating an improved environment along with innovative society and gaining competitive economic benefits for construction business with project stakeholders comprising with clients, architects, consultants, material manufacturing and supplying organisations, subcontractors and government are important (Shen et al., 2010). Out of these stakeholders, material manufacturing and supplying organizations play a significant role in the global construction industry consuming 300 metric tons of raw materials per year (Pacheco-Torgal and Labrincha, 2013). Concerning the Sri Lankan construction industry, SCI Report (2016); verified that 103.4Rs billions of raw materials consumed from all construction activities in 2015 with highest $20 \%$ weight was contributed from cement, under non-metallic mineral product manufacturing sector. As the fourth largest cement importing market in the world, Sri Lanka is estimated to remain a major importer with 3.3 million tons of domestic cement production. Hence, the competition between cement organisations is becoming more intensive (CMR Sri Lanka, 2017). Due to the above situation, Cement organisations' business is increasingly linked to various unethical business practices, such as ecological destruction, exploitation of labour, detriment on communities, and etc (Ulutaş, 2012). Presently Sri Lankan cement organisations typically develop CSR reports, conduct charitable work to expose their good corporate image in the cement industry. However, accepting what CSR means to cement organisations, and how to perform it, is limited (Zhao et al., 2012).

Hence, this study has focused to identify the Sri Lankan cement organisations' prevailing CSR practices. It has come into light that there is a gap between their current practice and required the practice of Corporate Social Responsibility (CSR) within their business process.

\section{LITERATURE REVIEW}

The term "sustainability" demonstrates the "ability to sustain", and sustainability is interweaved concept in the triple bottom line (Elkington, 1998). Hence, accepting 
sustainability for business process would address and lead to significant corporate benefits (Holton, 2009). Nevertheless, it presents that becoming more sustainable is as much about effective and gaining value for profit while protecting the environment and being responsible towards society (Holton, 2009). Nowadays, the concept of sustainability with its triple bottom line meaning is being adopted more and more by corporations (Holton, 2009). However, achieving corporate sustainability is a critical task (Holton, 2009). Developing for sustainability is weighted to be difficult for the improvement of corporate sustainability (Holton, 2009). Transposing the triple bottom line concept stated by Elkington (1998) to the corporate level, corporate sustainability can be defined as; improving corporate societal, ecological and economic achievement in a combined approach (Holton, 2009). Nevertheless, adopting corporate sustainability for business has become a priceless tool for identifying paths to control risky environment, and forecast essential inner changes in culture and corporate structure (Holton, 2009). The direction to achieve corporate sustainability the tool of Corporate Social Responsibility (CSR) was recognised as one of the milestone elements, which comprises corporate sustainability expression with worldwide business processes (Elkington, 1998).

CSR has been defined by ISO26000 as:

"The responsibility of an organisation for the impacts of its decisions and activities on society and the environment, through transparent and ethical behaviour"

Moreover, WBCSD (2009) argued; corporations must take full account of transparency for society and corporations to state responsively what their values are and to connect how well they live up to them. However, some corporations have converted the origin of CSR and they have accepted CSR as a defensive measure (Murray and Dainty, 2009) to enhance their corporate image and to attain economic benefits apart from improving corporate societal and environmental responsibilities (Zhao et al., 2012). Today, CSR goes far beyond the exact meaning and corporations have practised in the sections of CSR related to; business environment and process although CSR associated to philanthropic activities (Somachandra and Sylva, 2017). However, Carroll (1991), stated that CSR comprises philanthropic contribution (charity) but not restricted to them. Out of CSR activities, CSR related to business process is increasingly related to a number of direct impacts comprising economic, environmental and social. Due to above situation, WBCSD (2000) concentrated on evaluating the corporations' involvement towards sustainability in connection to their CSR actions within their business procedure.

Hence, WBCSD (2000) stated; the relationship between sustainability and CSR as:

"corporate commitment to contribute to sustainable economic development, employees and their families, local communities and the whole society in order to improve their quality of life" (WBCSD, 2000)

If CSR methodology integrated into the business process, the final outcome could be far wider than purely monetary profits (Murray and Dainty, 2009).

\subsection{The Cement Organisations' Business Processes}

The improved development of the key world economies outcomes in accelerating demand for the building materials (Pacheco-Torgal and Labrincha, 2013). As a consequence, the worldwide production of cement in 2030 is expected to grow to a stage nearly five times greater than its stage in 1990, with close to 5 billion tons (WWF International, n.d.) and it is difficult to imagine a modern life without cement (WBCSD, 2002). Cement is non- 
metallic mineral "adhesive" molded by mixing together with suitable natural particles such as limestone, iron mineral, bauxite and clay in a recognized quantities, heating them to a temperature of $1450^{\circ} \mathrm{C}\left(2640^{\circ} \mathrm{F}\right)$, and crushing the manufacturing product (clinker) with Gypsum to a powder (WBCSD, 2002). Apart from the production methodology, cement organisations' manufacturing procedure from the raw material extraction to final product introducing, its positive and harmful impacts towards the triple bottom line is significant (Zainudeen and Jeyamathan, 2004). In socio-economic viewpoint; cement industry generates numerous direct employment opportunities and provide a considerable contribution to the GDP (Zainudeen and Jeyamathan, 2004). Despite its acceptance and profitability, the cement industry aspects frequent barriers due to ecological harmful impacts and sustainability issues (Zainudeen and Jeyamathan, 2004). In socioenvironmental viewpoint; cement manufacturing is accepted as a high energy concentrated procedure and key provider to the worldwide $\mathrm{CO}_{2}$ emissions with $5 \%$ of total global $\mathrm{CO}_{2}$ amount (Verma, 2011). The breakdown of the emissions from cement production, Verma (2011) demonstrated; that $52 \%$ of green gas emissions resulting from process of making clinker and $36 \%$ of exhaust gasses $\left(\mathrm{NO}_{\mathrm{x}}\right.$, Chlorides, $\mathrm{SO}_{\mathrm{x}}$ and $\left.\mathrm{CO}\right)$ from incineration in the kiln. These releases have potential ecological impression causing global warming, ozone depletion, acid rain and reduced output of harvest (Verma, 2011). Nevertheless, above emissions are harmfully disturbing human health of cement factories' workers and local communities in several behaviours, like itchy eyes, breathing diseases like chest anxiety, asthma attacks and even premature death (Zainudeen and Jeyamathan, 2004). In the Cement manufacturing procedure, the estimated extraction quantities of raw materials were identified as; limestone 2470 ton/day and ground raw materials of nearly 2600 ton/day (Zainudeen and Jeyamathan, 2004). Thus, the main potential risks from cement manufacturing can be identified as; biodiversity losses in fauna and flora in and around the extraction site, dust, noise and vibration from material quarrying and explosives, conservation matters of cultural and heritage properties, and loss of livelihood (WBCSD, 2005). Apart from the frequent monetary benefits of the cement industry, due to the above harmful impacts, WBCSD (2005); stated that the cement manufacturing procedure and consumption regions form numerous challenges that threaten sustainability.

Further, it is necessary to achieve corporate sustainability in cement organisations' businesses under cement industry, and it was likely to make an essential involvement in the growth of sustainability in construction industry (WBCSD, 2005). Therefore, as argued by Mishra and Siddiqui (2014); the demand for cement is directly related to economic growth, and many growing economies are determining for rapid infrastructure progress in construction industry. Moreover, based on the cement organisations' contribution towards sustainability in the worldwide cement industry, some cement organisations have accepted CSR as an engine (Bhagwat, 2011) to attain economic benefits with improving corporate societal and environmental responsibilities towards sustainable development. One such implementation evident in Lafarge Holcim is to utilise waste-derived fuels and biomass as a replacement for fossil fuels to operate their cement kiln (Holcim, 2017). Therefore, Lafarge Holcim has become the most carbonefficient cement corporation among world-wide peers (Holcim, 2017). Apart from that, Heidelberg Cement has gone for group-wide training initiative for line managers through that they have reduced their accident occurrence frequency by $21 \%$ from 2016 to 2017 (Heidelberg, 2017). 
Turning towards the Sri Lankan context of cement production, Economics and Social Statistics of Sri Lanka (2017) stated that Sri Lanka is projected to be consuming about 5.8 million tons of cement per annum. Cement industrial corporations were contributing Rs .17 .97 billion to GDP in the $2^{\text {nd }}$ quarter of 2017 . Sri Lanka imports $66 \%$ of its cement requirement, either in the type of cement or clinker (Holey, 2014). In manufacturing procedure, wet and dry processes are used worldwide, and out of them, Sri Lanka is perhaps the only country in this region, which practices $100 \%$ dry procedure for cement production (Zainudeen and Jeyamathan, 2004). Moreover, Sri Lanka extents on one combined and three grinding cement manufacturing plants (CMR Sri Lanka, 2017). On the other hand, Sri Lanka imports cement from various plants in relations countries like India, Vietnam, Pakistan, Malaysia, Indonesia and Thailand (Holey, 2014).

Moreover, the importing of cement has to fulfil with the Sri Lankan Standards of Cement under the Sri Lanka Standard Institute (SLSI) (Holey, 2014). The SLSI has strict coordination in place to monitor the strict quality assurance system under the contribution towards socio-environment and following to appropriate corporate performs as well as holding the appropriate credentials is a must (Holey, 2014). The cement manufacturing and supplying organisation units in Sri Lanka are controlled by Tokyo Cement, SiamCity Cement, Heidelberg Cement and Ultratech, etc (CMR Sri Lanka, 2017) and these cement organisations usually publish details about CSR activities of philanthropic, business environment and business process in their annual business reports.

\section{METHODOLOGY}

On the path to achieving the research hypothesis, a wide-ranging literature review was established and the capacity and forms of exploration already achieved with related to CSR, sustainability and cement organisations' business process. A qualitative research approach has been adopted to compile this research. As the most accessible and practical data collection tool, interviews were accepted. Thereby, five leading cement organisations (02 manufacturers and 03 suppliers) in the Sri Lankan cement industry were interviewed. This sample has been selected based on 'Snowball' sampling method. Factory managers, Sustainable officers and Research and development officers were the main respondent group. Data analysis was based on transcribing, coding and categorising the qualitative data to build and finalize the conclusions of the study. Based on the data analysis; Cement organisations CSR practice could be categorised to three main categories as Philanthropic, Business Environment (BE) and Business Process (BP).

\section{RESULTS AND DISCUSSION}

During the qualitative data analysis carried out, based on the transcribing, coding and classifying through data analysis, it has implied the CSR activities in the cement organisations could be categorised under three main categories as; CSR through philanthropic activities, CSR related to business environment and CSR related to business process. When considering the general understanding on CSR from the respondents, it was exposed that; it is completely different from the exact concept of CSR under the triple bottom line concept stated by Elkington (1998) to the corporate level. Most of the respondents' explanations have weighted under the charity, donations, community need assessment and community helping works, etc. According to the respondent CON_03:

...CSR is like doing good, just genuinely doing good things like charitable works, donations, community helping works, but not something apart of the core business... 
Through the sample, it revealed that CSR has a deeper meaning contrary to the conventional idea of performing well within philanthropic activities. Thus, in the first instance, it is clear that; cement organisations' industrial general understanding of CSR is not properly established. Therefore, almost all the cement organisations had wrongly perceived that, CSR as comprising simply that philanthropic giving. However, while philanthropy can be defined as one element of CSR, it is completely not the situation that CSR is fitted to philanthropy only (UNESCAP, 2011). Therefore, it has come into light that, there is a misconception among cement organisations on the exact viewpoint of the integration of CSR and business operations.

\subsection{CSR Through Philanthropic ACTIVITIES}

Concerning on CSR through philanthropic activities, almost all the cement organisations' interviews have highlighted that; most of the CSR activities performed by cement organisations were focusing on philanthropic activities. However, Carroll (1991), specified that CSR doesn't limit only to charitable involvement.

As stated by CO_01:

...If you know, in Sri Lanka also when it comes to "Tsunami", our company has contributed for the Sri Lankan Government.

As stated by CO_03:

...so we donate a lot of cement for low-income families to build their houses and donations for religious activities...we give meals for poor schools in the factory area. And we build houses for "Tsunami" affected peoples and also war-displaced peoples...we help school children to learn music...

Hence, the identified philanthropic activities can be presented as; assessment of the families around the factory area that need houses and provide them with cement and other construction materials to build shelters, renovate canals, pre-schools and water tanks, facilitate; community halls, latrines and health clinic for the elderly community, implement cultural events and religious events to enhance the harmony among different ethnic groups, implement child protection and welfare programmes and charitable donations for people who faced with natural disasters like "tsunami", flooding. As per the above-identified activities, it was understood that; most of cement organisations' CSR through philanthropic activities are unfocused and diffuse. However, there is another important "Strategic Philanthropic" approach as evident by Porter and Kramer (2002). Further to that if this strategy fully incorporated in cement organisations' philanthropic contribution, it would direct to increase corporations' competitive advantages within creating good-will among society.

\subsection{CSR RELATED TO THE BUSINESS ENVIRONMENT}

When analysing CSR related to business environment practices of cement organisations, it has confirmed that; around $80 \%$ of respondents were implementing and continuing CSR related to business environment activities under the cement manufacturing and supplying operation in an effective manner. Thus, the identified business environment activities can be explained as; providing a range of employee welfare facilities, assist economic betterments; hospitalization insurance covers, the gratuity, pensions and post-retirement health compensations, provide the job related basic requirements; accommodations, meals, uniforms, personal protective equipment (PPE) and the implementation 
programmes, such as get-togethers, annual trips to motivate the employees' focusing on their happiness and satisfaction.

Moreover, almost all cement organisations had given highest concentrate about their employees and one of the respondents, i.e. CO_03, stated that;

...Our workers are a core corporate asset and a competitive benefit, and as such, the corporation sustained to contribute in their training, improvement and well-being...

Further to that, they were provided national and international trainings of general training methods, training in health and safety to upgrade and enhance the productive skills of employees. Thus, awareness was conducted through maintaining occupational health and safety standards, assigning safety managers for each production task, illustrate safety notices and posters, provide PPE, and conduct weekly toolbox meetings. Apart from the cement organisations' concern under the improvement of employees' productivity, one organization has applied an open door grievance management systems to communicate difficulties of any employee under their factory. Nevertheless, it certifies employee privacy joined with reasonable action of all employees regardless of age, sex, religion or ethnicity.

According to CO_02;

...In factory workers side, there is an open door grievance mechanism, they can reach top management in their problematic matters...

On the path to achieve corporate sustainability, corporations will have to focus on "Social Capital" concept, and it can be defined as content of connections between employees as well as corporations' entities (Dyllick and Hockerts, 2002). Through these explanations, it was understood that; cement organisations didn't have thorough understanding of the word "Social Capital". However, they have achieved and initiated actions which direct to adapt "Social Capital" through CSR related to business environment activities.

\subsection{CSR Related TO BUSINESS PROCESS}

When assessing, it was acknowledged that CSR concerning business process activities of cement organisations had accepted and confirmed that around $80 \%$ of the respondents do not have clear idea about CSR related business process activities and they have adopted that as day-to-day operational activities within legal and standardised necessities in cement industry. Consequently, their understandings on actions like; standardising with government institutions' environmental permits, rules and regulations under manufacturing procedure, complying with the Sri Lankan Standards of importing cement under SLS, maintaining ISO standards, maintaining greenery around the factory area, , proper housekeeping, internal auditing procedure, etc.

As stated by CO_02:

... Yes, we have obtained ISO 14001:2004 certification, we will study, all the environmental impacts according to the government rules and regulations, monitoring stack emissions, and production noise, dust everything being monitored...

Moreover, apart from the cement organisations' above compliance with acceptance on industrial laws and regulation, accepting what CSR means to business process and how to perform it is limited. Therefore, CSR can be much more than a day-to-day operation and it is not an exclusive matter of mandated practices under legal and standards on cement industry. It is something beyond that organisations fix to improve above existing 
practices incorporating sustainability for long-term outputs. During the focus group interview held with a person who worked at the above cement organisation, stated that;

"In the last few months, I was worked in this cement factory. The dust from the factory were effected on the "Kadolana" trees in wetland area near the factory."

WBSCD (2009) stated that; on the path to realise the transparency of the business process, corporations have to state responsively on what their business process is based on. Within this sense, according to focus group interview data, it signifies that, attention towards a morally obliged business process practice within considerateness on environmental impact mitigation lacked among cement organisations. Considering the environmental management systems (EMS) in cement manufacturing, it can be identified that it is a crucial factor which impacts on the production cycle of cement. However, limited responsiveness from the sample on EMS, revealed by one organisation implementing new EMS concept to reduce a resource depletion from their business process. As stated by $\mathrm{CO}$ 03:

...we take this samples of concrete based being wastes, and so we came up with the concept of the making reef-like structures, and they are coral reef balls...we maintain coral necessaries and do plants...so the coral grows, coral act as a carbon sink and the carbon is accumulated, because we burn the limestone to produce cement, it's a creation of the limestone back to nature...

Subsequently, within this practice, this organisation had also been indirectly involved with one of the environmental aspects with regard to coral rehabilitation. Further to that, other organisations had not utilised any new concepts in EMS scope beyond the legal requirements. In the direction to attain corporate sustainability through CSR, corporations will have to apply sustainable innovations, and it can be defined as a procedure wherever sustainability considerations (ecological, societal, and economic) are combined into corporation arrangements from strategy creation through to investigation and improvement and commercialisation (Katerva, 2019).

Thus, CSR can lead to the application of innovative mind thorough the use of sustainable innovative drivers to create new products, services and process (Tello, S. and Yoon, E, 2014). Within the above sense, evaluating sustainable innovative performance is an essential factor. However, according to the sample, under limited awareness; only two cement organisations have applied and practised sustainable innovative solutions, which will be discussed below. Among them, one cement organisation has applied an innovative solution to operate its cement kiln from waste-derived fuels. As stated by CO_02:

...we take all the industrial waste from the construction and other industrial zones and some industrial factories likewise and we re-processing it and feeding it in to our kiln as a fuel around 30\% -35\% from the waste. So, that is the biggest advantage not only for us for the country we provide very good solution for the waste...

Meanwhile, the above practice directs the energy efficiency under sustainability, and it provides identically a good solution for the construction industry waste management.

Moreover, from material excavation at the quarry until bagged cement loading process, it results in un-productive waste streams like gaseous and energy waste streams. Thus, solid and liquid waste streams are very rare in dry kiln process under Sri Lankan cement organisations. Out of these streams, energy conservation is a key factor in sustainability and in path to achieve this factor. The data revealed that amongst the two, there's only 
one cement organisation involving in an innovative idea addressing energy conservation. As stated by CO_03:

...we have agriculture waste biomass power plants...In cement manufacturing, biomass burning, and we have steam-generating with steam turbines and produce energy. But that ash in again porcelain silica ash being used in cement manufacturing. So it's a closed cycle procedure which gives energy and a like zero waste energy generation method.

Thus, this organisation had fulfilled their groups' energy requirements by renewable biomass energy initiative without burdening the national power grid. It was observed that; remaining organisations in the sample have not taken any steps to develop the integration of the sustainable innovations for business process. Through these explanations, it was understood that cement organisations' main consideration is settled in market-place contest which measures the socio-economic performance characteristic within day-to-day operation. Nevertheless, the application of sustainable innovations in assessing ecological performance traits was not focusing well by the cement organisations.

\section{CONCLUSIONS AND RECOMMENDATIONS}

The study revealed that most of the Sri Lankan cement organisations' industrial general understanding on CSR is not properly established and they had wrongly perceived that, CSR as comprising simply that philanthropic giving. Therefore, it has come into light that, there is a misconception among cement organisations on the exact viewpoint of the integration of CSR and business operations. Thus, it was found that; almost all the cement organisations' CSR related to philanthropic and business environment involvement were at highest level, and there is a significant lacking point in the current practices of CSR linked to the business process. Moreover, compared to the worldwide cement industrial leaders' CSR related business process, Sri Lankan cement organisations are not very much involved and concerned about the application of sustainable innovations for their business process. Therefore, the entire cement industry needs to think beyond its current focus on market position competition under short-term monetary benefits and think about a morally obliged business process practice and the long-term win-win opportunities under the application of sustainable innovations on their business process. Thus, there is an emerging need of a proper framework or guideline addressing the above lacking situations on Sri Lankan cement organisations. In the direction to achieve morally obliged business process practice of cement organisations, environmental institutions under the government have a significant role to play in certifying that cement organisations behaviour allowing to the legal necessities and standards for improving corporate societal and environmental responsibilities towards sustainable development in the cement industry. Thus, they can legislate, foster, collaborate with cement organisations' businesses and endorse good practise to facilitate the improvement of accepting what CSR means to business process. Hence, establishing a "Sustainable Development institute of Cement" to verify Sri Lankan contribution towards production within sustainability would be of vital importance. It will be beneficial to control, associate institutes like cement organisations, dealers and suppliers to continue and support earlystage assessment to improve and evaluate innovative and latest business process mechanisms. Work together with small to high scale production chains from cement companies to minimise risk and accelerate the growth of advanced inventions.

Furthermore, a morally obliged business practice can enrich by improving research and development innovations for effective use of resources, use of alternative fuels and 
alternative raw materials within the cement manufacturing process. Further innovative practices were proposed by WBCSD (2002); as semi-open cut mining innovative method to develop precise quarry mining plans that optimize raw material extraction and liner extraction, vastly energy-efficient procedure tools like rotary kiln or solar kiln, alternative energy forms for cement production process, monitoring of air pollution and use innovative manage and detect tools; SNCR (selective non-catalytic reduction systems) to reduce NOX emissions and pulse-jet filters in kiln points at cement producing plants. Moreover, the WBCSD (2002), conducted extensive research with ten major cement organisations' sustainable innovations within business process across the world and they had recommended actions under "Toward a Sustainable Cement Industry" report to establish the internal and external process that facilitate more sustainable practices under the business process. Thus, it is necessary to accept this recommended guideline to fulfil the gap between current practice and required practice of CSR within their business process to achieve sustainability in the Sri Lankan cement organisations' businesses under cement industry and it was likely to make a vital impact on the development of sustainability in the Sri Lankan construction industry.

\section{REFERENCES}

Bal, M., Bryde, D., Fearon, D. and Ochieng, E., 2013. Stakeholder Engagement: Achieving Sustainability in the Construction Sector. Sustainability, 5(2), pp.695-710.

Bhagwat, P., 2011. Corporate social responsibility and sustainable development. In Proceedings of the Articles and Case Studies: Inclusive \& Sustainable Growth Conference. 1 (1).

CMR Sri Lanka, 2017. Cement market report: Sri Lanka. CW Research.

Dyllick, T. and Hockerts, K., 2002. Beyond the business case for corporate sustainability. Business Strategy and the Environment, 11(2), pp.130-141.

Department of Census and Statistics, 2017. Sri Lanka Labour Demand Survey, Department of Census and Statistics, Ministry of National Policies and Economic Affairs, Sri Lanka.

Economics and Social Statistics of Sri Lanka, 2017. Central Bank of Sri Lanka, Statistics Department.

Elkington, J., 1998. Partnerships from cannibals with forks: The triple bottom line of $21^{\text {st }}$-century business. Environmental Quality Management, 8(1), pp.37-51.

Heidelberg, C., 2017. Sustainability Report. [online] Heidelberg Cement. Available at: http://www.heidelbergcement.com/responsibility [Accessed 17 September 2018].

Holcim, L., 2017. Sustainability Report. LAFARGE HOLCIM.

Holey, S., 2014. Understanding Sri Lanka's cement industry from a customer's perspective. The Sunday Times.

Holton, I., 2009. Developing a sector sustainability strategy for the UK precast concrete industry. Undergraduate. Loughborough University.

ISO, 2010. 26000 Guidance on social responsibility. Ginebra: ISO.

Katerva, 2019. Sustainable Innovation. [ebook] Available at: https://katerva.net/about/sustainableinnovation [Accessed 20 February 2019].

Mishra, S. and Siddiqui, N.A., 2014. A review on environmental and health impacts of cement manufacturing emissions. International Journal of Geology, Agriculture and Environmental Sciences, 2(3), pp.26-31.

Murray, M. and Dainty, A., 2009. Corporate Social Responsibility in the Construction Industry. $1^{\text {st }}$ ed. Hoboken: Taylor and Francis.

Pacheco-Torgal, F. and Labrincha, J., 2013. The future of construction materials research and the seventh UN Millennium Development Goal: A few insights. Construction and Building Materials, 40, pp.729737.

Porter, M. and Kramer, M., 2002. The Competitive Advantage of Corporate Philanthropy. Harvard Business Review. 
SCI Report, 2016. Department of Census \& Statistics. Available at: http://www.statistics.gov.lk/industry/SCI_Final_Report_2016.pdf [Accessed 10 August 2018].

Shen, L., Tam, V., Tam, L. and Ji, Y., 2010. Project feasibility study: the key to successful implementation of sustainable and socially responsible construction management practice. Journal of Cleaner Production, 18(3), pp.254-259.

Somachandra, V. and Sylva, K., 2018. Construction industry focus towards sustainability through corporate social responsibility. In: International Conference of Disaster Management. Indonesian Disaster Expert Association.

Tello, S. and Yoon, E., 2014. CSR reporting on the corporate commitment to sustainable innovation. International Journal of Strategic Management, 14(1), pp.71-82.

Tradesmen International, 2018. Construction Industry Growth Trends Through 2020| Tradesmen.

Ulutaş, D., 2012. Corporate social responsibility in construction industry (Doctoral Dissertation).

UNESCAP, 2011. Promoting Sustainable and Responsible Business in Asia and the Pacific. ESCAP Studies in Trade and Investment.

Verma, M., 2011. New Trends in Environmental and Socially Responsible Management in the Cement Manufacturing. Undergraduate. University of Bradford, U.K.

Warakapitiya, K., 2016. Industrial accidents on the rise. The Sunday Times.

World Business Council for Sustainable Development, 2000. Corporate Social Responsibility: Making Good Business Sense. Geneva: World Business Council for Sustainable Development.

World Business Council for Sustainable Development, 2002. Toward a Sustainable Cement Industry. [online] World Business Council for Sustainable Development. Available at: https://www.wbcsdcement.org/pdf/battelle.pdf [Accessed 10 Sep. 2018].

World Business Council for Sustainable Development, 2005. Cement Sustainability Initiative (CSI). Environmental and social impact assessment (ESIA) guidelines.

World Business Council for Sustainable Development, 2009. Corporate Social Responsibility: Making Good Business Sense. Geneva.

World Wildlife Fund International (n.d.). A blueprint for a climate friendly cement industry. [online] Gland, Switzerland: WWF International.

Zainudeen, N. and Jeyamathan, J. (2004). Cement and its effect to the environment: A case study in Sri Lanka. Department of Building Economic, University of Moratuwa (2004), pp.1408-1416

Zhao, Z., Zhao, X., Davidson, K. and Zuo, J., 2012. A corporate social responsibility indicator system for construction enterprises. Journal of Cleaner Production, 29-30, pp.277-289. 